\title{
Instability of 2,2-di(pyridin-2-yl)acetic acid. Tautomerization versus decarboxylation
}

\author{
Piotr Borowski • Ryszard Gawinecki • \\ Anna Milaczewska • Agnieszka Skotnicka • \\ Krzysztof Woliński • Agnieszka Brzyska
}

Received: 15 March 2010 / Accepted: 4 June 2010 / Published online: 1 July 2010

(C) The Author(s) 2010. This article is published with open access at Springerlink.com

\begin{abstract}
The DFT calculations at the B3LYP level with 6$311 \mathrm{G}^{* *}$ basis set were carried out in order to reveal whether tautomerization or decarboxylation is responsible for the instability of 2,2-di(pyridin-2-yl)acetic (DPA) and 1,8-diazafluorene-9-carboxylic (DAF) acids. The carboxyl protons in both compounds are involved in the intramolecular hydrogen bonds (the pyridine nitrogen atoms are the hydrogen bond acceptors). Although formation of two intramolecular $\mathrm{OH}^{\cdots} \mathrm{N}$ hydrogen bonds in the enols of both carboxylic acids enables effective electron delocalization within the quasi rings $(\cdots \mathrm{HO}-\mathrm{C}=\mathrm{C}-\mathrm{C}=\mathrm{N})$, only ene-1,1diol of DAF has somewhat lower energy than DAF itself $\left(\Delta \mathrm{E}\right.$ is $\left.c a .7 \mathrm{kcalmol}^{-1}\right)$. DPA and its enediol have comparable energies. Migration of the methine proton toward the carbonyl oxygen atom (to form enediols) requires overstepping the energy barriers of 55-57 kcal $\mathrm{mol}^{-1}$ for both DPA and DAF. The enaminone tautomers of the acids, formed by migration of this proton toward the pyridine nitrogen atom, are thermodynamically somewhat more stable than the respective enediols. The energy barriers of these processes are equal to $c a .44$ and $62 \mathrm{kcal}$ $\mathrm{mol}^{-1}$ for DPA and DAF, respectively. Thus, such tautome-
\end{abstract}

P. Borowski $(\bowtie) \cdot$ A. Miłaczewska $\cdot$ K. Woliński $\cdot$ A. Brzyska Department of Chemistry, Maria Curie-Skłodowska University, pl. Marii Curie Skłodowskiej 3,

20-031, Lublin, Poland

e-mail: pibcio@vsop401.umcs.lublin.pl

R. Gawinecki $(\bowtie) \cdot$ A. Skotnicka

Department of Chemistry,

University of Technology and Life Sciences,

Seminaryjna 3,

85-326, Bydgoszcz, Poland

e-mail: gawiner@utp.edu.pl rization of the acids is not likely to proceed. On the other hand, the distinct energetic effects (ca. $15 \mathrm{kcalmol}^{-1}$ ) favor decarboxylation. This process involves formation of $(E)-2-$ (pyridin-2(1H)-ylidenemethyl)pyridine and its cyclic analogue followed by their tautomerization to (dipyridin-2-yl) methane and 1,8-diazafluorene, respectively. Although the later compound was found to be somewhat thermodynamically more stable, kinetic control of tautomerization of the former is more distinct.

Keywords Carboxylic acids · Decarboxylation - DFT calculations $\cdot$ Reaction path $\cdot$ Tautomerization $\cdot$ Transition states

\section{Introduction}

Ene-1,1-diols, often called enols of carboxylic acids, are intermediates in hydration of ketenes [1,2]: $\mathrm{R}_{2} \mathrm{C}=\mathrm{C}=\mathrm{O}+$ $\mathrm{H}_{2} \mathrm{O} \rightarrow \mathrm{R}_{2} \mathrm{C}=\mathrm{C}(\mathrm{OH})_{2} \rightarrow \mathrm{R}_{2} \mathrm{CH}-\mathrm{CO}_{2} \mathrm{H}$. These compounds are less stable then the corresponding carboxylic acids being energetically favored by delocalization of the lone electron pair of the hydroxy oxygen atom (Fig. 1) [1]. It is known, however, that ene-1,1-diols that contain bulky aromatic groups in the molecule, are more stable [1-4]. The hindered protonation of the $\beta$ carbon atom in $\mathrm{Ar}_{2} \mathrm{C}^{\beta}=$ $\mathrm{C}(\mathrm{OH})_{2}$ caused by ortho alkyl groups ( $\mathrm{Ar}=2,4,6$-trimethylphenyl, 2,4,6-triisopropylphenyl or 2,3,4,5,6-pentamethylphenyl) is responsible for such a behavior. Enediol of cyclopentadiene-1-carboxylic acid (Fig. 2) was found to be relatively stable [5]. Two intramolecular hydrogen bonds of the resonance-assisted hydrogen bond (RAHB) type [6-9] are expected to be present in its derivative annulated with two pyridine rings (Fig. 3). Unfortunately, neither 1,8diazafluorene-9-carboxylic (9H-cyclopenta[1,2-b;3,4-b'] 
<smiles>C=CC(=O)C(C)C(C)C(=O)O</smiles>

Fig. 1 Relation between carboxylic acids and ene-1,1-diols

Fig. 2 Cyclopentadiene-1carboxylic acid and its enol

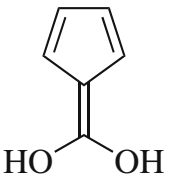

dipyridine-9-carboxylic) acid nor its enol are known, but close analogue of the former compound, 2,2-di(pyridin-2-yl) acetic acid, was claimed to be obtained earlier from 2-diazo1,2-di(pyridin-2-yl)ethanone [10]. Since numerous heterocyclic acetic acids are potentially interesting as anti-arthritic agents [11, 12], the compounds mentioned above seem worthy to be studied from point of view of their stability.

Loosing of the $\mathrm{CO}_{2}$ molecule by 2- and 4-pyridylacetic acids proceeds smoothly even below $100{ }^{\circ} \mathrm{C}$ (this process is much more difficult for 3-pyridylacetic acid) [11-17]. 2(Pyridin-2- and 4-yl)phenylacetic acids are also exceptionally unstable: benzylpyridines were found to be the only products of the acid hydrolysis of 2-(pyridin-2- and 4-yl) phenylacetonitriles [18]. On the other hand, the enediol and enaminone tautomeric forms of the closely related 2,2-di (pyridin-2-yl)acetic acid (Fig. 4) can be stabilized by two intramolecular hydrogen bonds. Its tendency to decarboxylate is not reported in the only paper devoted to synthesis and properties of this compound [10].

Decarboxylation of carboxylic acid involves formation of carbon dioxide and an organic residue [16]. Organic product is usually stabilized by delocalization of its unshared electron pair. Formation of the intermediate zwitterion $\mathrm{HOCO}-\mathrm{C}_{5} \mathrm{H}_{4} \mathrm{~N} \rightarrow{ }^{\ominus} \mathrm{OCO}-\mathrm{C}_{5} \mathrm{H}_{4} \mathrm{~N}^{\oplus} \mathrm{H}$ is a common step in the mechanism of enzyme-catalyzed decarboxylations of 2- and 4-pyridylacetic acids [12, 14, 17]. Electron delocalization is particularly important in enzymatic reactions, where an "electron sink" is generally provided by a coenzyme [16].

Fig. 3 Relation between 1,8diazafluorene-9-carboxylic acid and its enol<smiles>O=C1O[Tl]c2ncccc2-c2cccnc21</smiles>

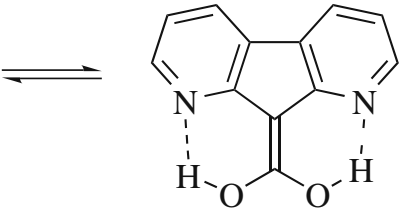

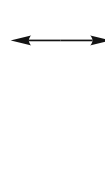

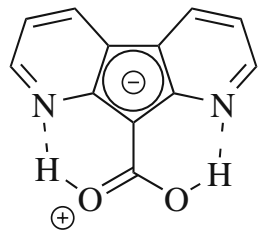<smiles>[R]c1cccnc1C1C(=O)O[Y]2cccc([R])c21</smiles><smiles>C1=CCC1</smiles><smiles></smiles><smiles>C1=CCCCC1</smiles>

Fig. 4 Relation between 2,2-di (pyridin-2-yl)acetic $(\mathrm{R}=\mathrm{H})$ and and 1,8-diazafluorene-9-carboxylic $(\mathrm{R}=$ none $)$ acids and its tautomers 
Despite their instability, the labile compounds may appear as intermediates in numerous (bio)chemical processes. Explanation what are the products these derivatives are transformed to, seems very important. Numerous attempts done in our laboratory to obtain 2,2-di(pyridin-2yl)acetic acid (1a, Fig. 5) from 2-diazo-1,2-di(pyridin-2-yl) ethanone according to the known procedure [10] as well as by hydrolysis of 2,2-di(pyridin-2-yl)acetonitrile (the standard procedure) were unsuccessful. Irrespective of the reason of inaccessibility of this compound to us, its properties can still be discovered by quantum chemical calculations. In the present paper 2,2-di(pyridin-2-yl)acetic (1a) and 1,8-diazafluorene-9-carboxylic (1b) acids are considered to be susceptible to tautomerization and decarboxylation. The related pyridylacetic acids were used earlier as the models when studying decarboxylation mechanism of aminoacids [19]. It is noteworthy that numerous heterocyclic derivatives of acetic acid are potentially interesting as anti-arthritic agents [20].

\section{Computational details}

Density functional theory (DFT, see, e.g., [21]) has been recognized for years to be capable of predicting the very accurate conformations of the covalently bonded systems. Thus, its use in the present paper is justifiable. All calculations were carried out using B3LYP hybrid functional $[22,23]$ with the $6-311 \mathrm{G}^{* *}$ basis set [24].

Formulas of 2,2-di(pyridin-2-yl)acetic (1a) and 1,8diazafluorene-9-carboxylic (1b) acids, their enol $(\mathbf{2 a}, \mathbf{b})$ and enaminone $(\mathbf{3 a}, \mathbf{b})$ tautomeric forms as well as the (expected) intermediates $(\mathbf{4 a}, \mathbf{b})$ and final products of the decarboxylation process $(\mathbf{5 a}, \mathbf{b})$ are depicted in Fig. 5, which also shows numbering of heavy atoms. It should be noted that the carboxyl hydrogen atom H9 (in 1, 2 and 3) has the same number even if it is bound to N1 (in 4) or C7 (in 5). Formulas of the transition states that are (or may be) formed during decarboxylation of $\mathbf{1 a}$ and $\mathbf{1 b}$ can be seen in Fig. 6. The geometry optimization of all substrates, products and transition states was carried out first. Then, the harmonic frequencies were calculated to establish the types of stationary points, and to find the zero-point energy (ZPE) corrections for the energy barriers and the energetic effects of the processes investigated in the present work. All frequencies for systems $\mathbf{1}-\mathbf{5}(\mathbf{a}, \mathbf{b})$ were real. On the other hand, one imaginary frequency was found for transition states TS(1-4) a,b. Analysis of the eigenvectors corresponding to the imaginary frequencies provided us with the information about the possible products "on each side" of a transition state at a given stage of the reaction.

Geometry optimization for the transition state is much more complex than for the stable system. This prompted us to carry out some initial, point-wise calculations, corresponding to the so-called distinguished reaction coordinate (DRC). This procedure is not recommended for the accurate description of the reaction path, for example on account of possible discontinuities of energy (and geometrical parameters) as a function of DRC (i.e., some selected geometrical parameter, e.g., bond length). It may, however, provide a reasonable initial structure for which typical algorithms are capable of converging quickly to the required transition state. Therefore, the

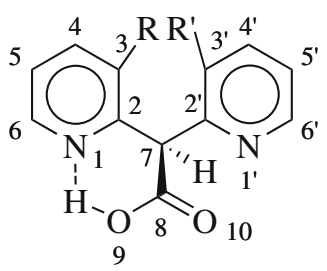

1a, b<smiles></smiles>

2a, b

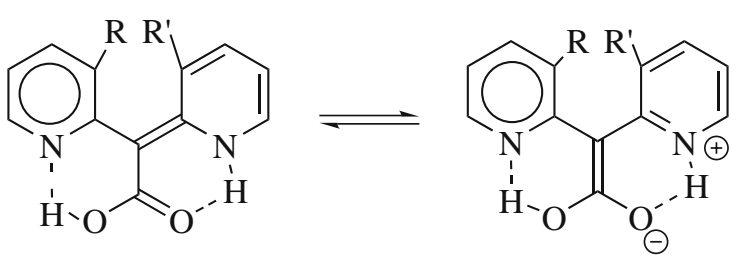

3a, b<smiles>[R]C1=CC=CN/C1=C/c1ncccc1[R]</smiles>

4a, b

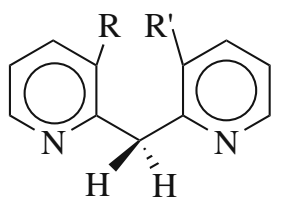

5a, b

$\mathrm{R} / \mathrm{R}^{\prime}=\mathrm{H} / \mathrm{H}$ (a) or none (b)

Fig. 5 Formulas of the compounds studied and the numbering of the heavy atoms 
Fig. 6 Formulas of the transition states studied in this work<smiles></smiles>

TS1a, b<smiles></smiles>

TS2a, b<smiles>[R]c1cccnc1[C@H](C(=O)O)c1[nH+]cccc1[R]</smiles>

TS3a, b<smiles></smiles>

TS4a, b

$\mathrm{R} / \mathrm{R}^{\prime}=\mathrm{H} / \mathrm{H}$ (a) or none $(\mathbf{b})$

C7C8 bond was selected as the DRC in reactions $\mathbf{1} \rightarrow \mathbf{4 +}$ $\mathrm{CO}_{2}$. Its length, $R$, was gradually increased from the equilibrium value found for $\mathbf{1}$ (the applied increment was $0.1 \AA$ ), the remaining parameters were optimized, and the geometry corresponding to the highest energy was determined. Since H9 turned out to still be bound to the carboxylic oxygen atom, it was placed in the middle of the O9 $\cdots \mathrm{N} 1$ distance prior to running the transition state search. On the other hand, the two internal coordinates $r_{1}=\mathrm{H} 9 \mathrm{~N} 1$ and $r_{2}=\mathrm{H} 9 \mathrm{C} 7$ (cf. Fig. 5) were selected for the description of the proton migration in the $\mathbf{4} \rightarrow \mathbf{5}$ tautomerization. Energies of structures optimized for the remaining geometrical parameters were then computed at a grid of selected linearly independent points. Then, the cross-section of PES (see
Fig. 7 for an example), approximated by the $3^{\text {rd }}$ degree polynomial, was subjected to straightforward search of the saddle point. All initial structures obtained in this way turned out to converge quickly to the corresponding transition states by following (maximizing along) the lowest (negative) Hessian eigenmode. In order to follow the reaction paths, concept of the so-called intrinsic reaction coordinate (IRC) [25] in mass-weighted Cartesian coordinates was used. All calculations were carried out with the parallel version of the PQS quantum chemistry package [26, 27].

\section{Results and discussion \\ Molecular geometries}

The optimized structures of carboxylic acids as well as these of the enol and enaminone tautomeric forms and products of their decarboxylation (dipyridyl-2-ylmethane and its 1,2-dihydro tautomeric form) are depicted in Fig. 8. Their most important geometrical parameters, as well as geometrical parameters of the transition states $\mathbf{T S}(\mathbf{1 - 4}) \mathbf{a}, \mathbf{b}$ are presented in Tables 1 and 2.

The most significant conclusions regarding the molecular geometries are as follow:

1. Arrangement of the $\mathrm{N} 1$ and $\mathrm{N} 1^{\prime}$ atoms in the most stable conformer of 2,2-di(pyridin-2-yl)acetic acid 1a is trans-like relative to the $\mathrm{C} 2 \mathrm{C} 7 \mathrm{C} 2{ }^{\prime}$ link (Fig. 8). Turning of one pyridine ring in $\mathbf{1 a}$ by $\mathrm{ca} .90^{\circ}$ around the $\mathrm{C} 7 \mathrm{C} 2^{\prime}$ bond increases the energy by only $0.3 \mathrm{kcalmol}^{-1}$. Linking of the pyridine rings via the $\mathrm{C} 3 \mathrm{C} 3^{\prime}$ bond in 1b prevents their free rotation and makes the molecule rigid. Note that the $\mathrm{N} 1 \mathrm{C} 2 \mathrm{C} 7 \mathrm{C} 2^{\prime}$ and $\mathrm{N} 1{ }^{\prime} \mathrm{C} 2{ }^{\prime} \mathrm{C} 7 \mathrm{C} 2$ torsion angles in $\mathbf{1 b}$ are close to $180^{\circ}$, i.e., the pyridine rings in the molecule are nearly coplanar. The hydroxyl

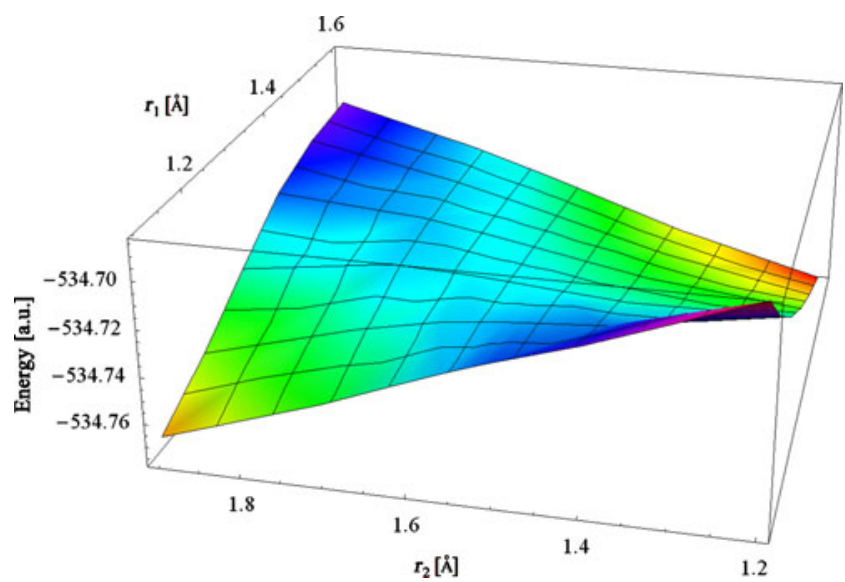

Fig. 7 The cross-section of the potential energy surface (PES) corresponding to the proton migration in $\mathbf{4 a} \rightarrow \mathbf{5 a}$ reaction (see text for the definition of the internal coordinates) 

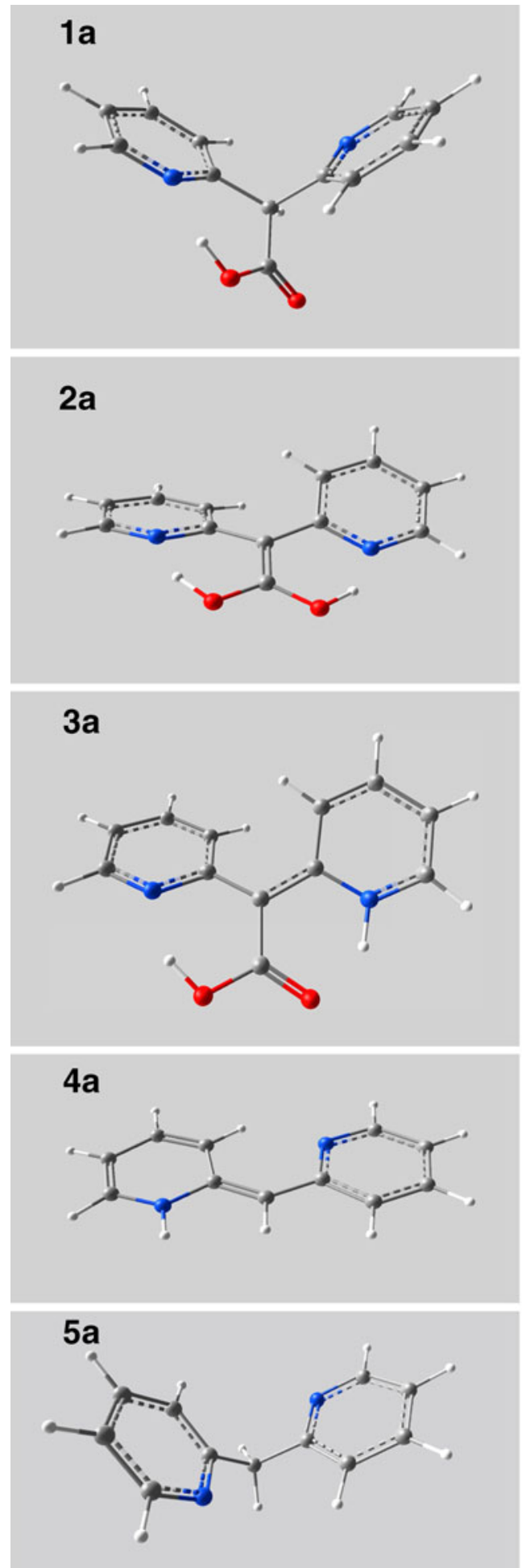

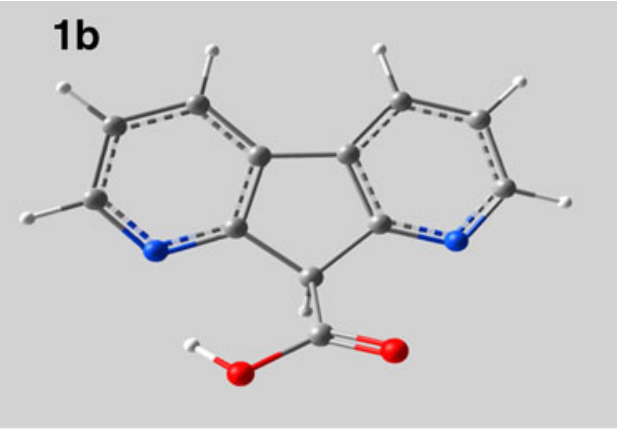

$2 b$
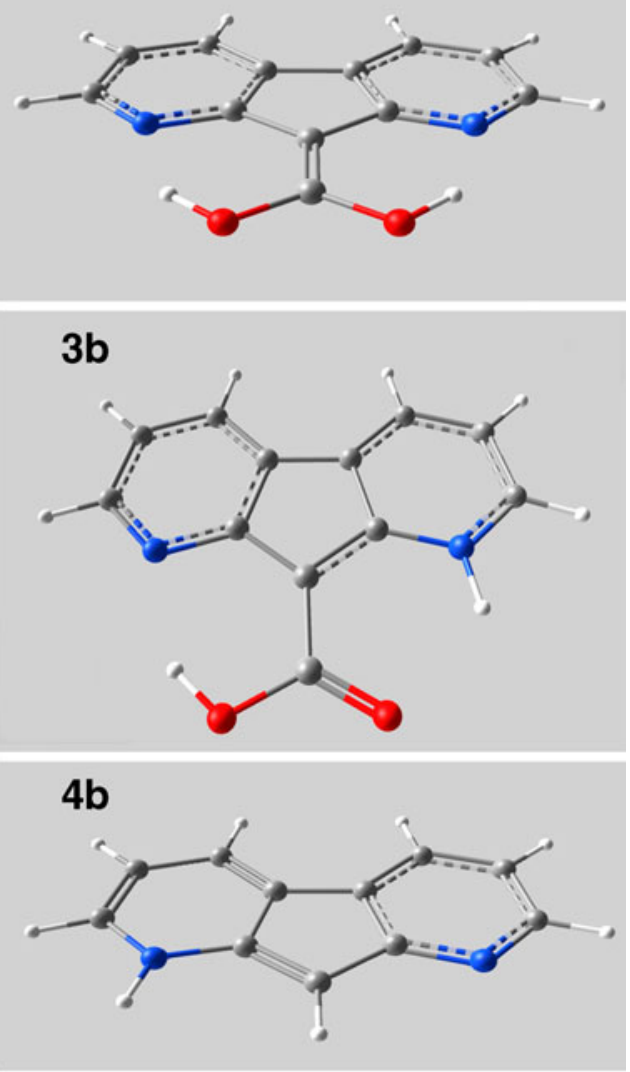

$5 b$

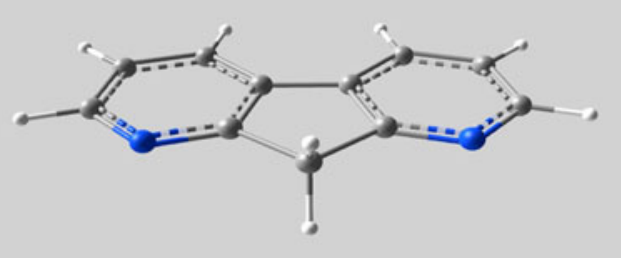

Fig. 8 Optimized structures of the substrates and products of the tautomerization/decarboxylation processes

groups both in $\mathbf{1 a}$ and $\mathbf{1 b}$ are involved in the intramolecular hydrogen bond with the $\mathrm{N} 1$ atom being the hydrogen bond acceptor. The $\mathrm{OH}$ bond in 1a is somewhat longer than $0.99 \AA$ (a typical $\mathrm{OH}$ bond length in the dimers of ordinary carboxylic acids where very strong intermolecular hydrogen bonds are present). On the other hand, the $\mathrm{OH}$ bond in $\mathbf{1 b}$ is shorter (ca. 0.98 $\AA$ ). Rigidity of the $\mathbf{1 b}$ molecule and, consequently, steeper 
Table 1 Selected optimized (B3LYP/6-311G**) bond lengths $[\AA]$ as well as valence and torsion angles [deg] in compounds 1-5

\begin{tabular}{|c|c|c|c|c|c|c|c|c|c|c|}
\hline Bond/angle & $1 \mathrm{a}$ & $1 b$ & $2 \mathrm{a}$ & $2 b$ & $3 a$ & $3 b$ & $4 a$ & $4 b$ & $5 a$ & $5 \mathrm{~b}$ \\
\hline О9H9 & 0.993 & 0.981 & 1.021 & 0.990 & 1.000 & 0.981 & - & - & - & - \\
\hline N1H9 & 1.738 & 1.918 & 1.572 & 1.965 & 1.654 & 2.005 & 1.009 & 1.009 & - & - \\
\hline $\mathrm{O} 10 \mathrm{H} 7$ & - & - & 1.021 & 0.990 & 1.606 & 2.138 & - & - & - & - \\
\hline N1'H7 & - & - & 1.572 & 1.965 & 1.047 & 1.021 & - & - & - & - \\
\hline $\mathrm{C} 8 \mathrm{O} 10$ & 1.201 & 1.195 & 1.306 & 1.315 & 1.238 & 1.223 & - & - & - & - \\
\hline C8O9 & 1.339 & 1.345 & 1.306 & 1.315 & 1.328 & 1.344 & - & - & - & - \\
\hline C7H7 & 1.089 & 1.098 & - & - & - & - & 1.087 & 1.079 & 1.091 & 1.095 \\
\hline C7H9 & - & - & - & - & - & - & - & - & 1.091 & 1.095 \\
\hline $\mathrm{C} 7 \mathrm{C} 2$ & 1.523 & 1.513 & 1.462 & 1.433 & 1.467 & 1.436 & 1.375 & 1.372 & 1.517 & 1.511 \\
\hline $\mathrm{C} 7 \mathrm{C} 2^{\prime}$ & 1.534 & 1.514 & 1.462 & 1.433 & 1.415 & 1.387 & 1.444 & 1.441 & 1.517 & 1.511 \\
\hline $\mathrm{C} 7 \mathrm{C} 8$ & 1.546 & 1.550 & 1.419 & 1.376 & 1.479 & 1.450 & - & - & - & - \\
\hline N1C2 & 1.340 & 1.325 & 1.359 & 1.338 & 1.356 & 1.341 & 1.402 & 1.377 & 1.340 & 1.326 \\
\hline N1C6 & 1.338 & 1.344 & 1.336 & 1.340 & 1.335 & 1.336 & 1.365 & 1.363 & 1.337 & 1.342 \\
\hline $\mathrm{N} 1^{\prime} \mathrm{C} 2^{\prime}$ & 1.338 & 1.323 & 1.359 & 1.338 & 1.380 & 1.359 & 1.355 & 1.343 & 1.340 & 1.326 \\
\hline $\mathrm{N} 1{ }^{\prime} \mathrm{C} 6^{\prime}$ & 1.335 & 1.341 & 1.336 & 1.340 & 1.350 & 1.356 & 1.333 & 1.334 & 1.337 & 1.342 \\
\hline $\mathrm{C} 2 \mathrm{C} 3$ & 1.397 & 1.407 & 1.415 & 1.428 & 1.414 & 1.433 & 1.445 & 1.469 & 1.399 & 1.412 \\
\hline $\mathrm{C} 3 \mathrm{C} 4$ & 1.389 & 1.391 & 1.383 & 1.389 & 1.384 & 1.389 & 1.360 & 1.367 & 1.390 & 1.391 \\
\hline $\mathrm{C} 4 \mathrm{C} 5$ & 1.394 & 1.396 & 1.398 & 1.398 & 1.396 & 1.395 & 1.432 & 1.423 & 1.392 & 1.394 \\
\hline C5C6 & 1.388 & 1.393 & 1.384 & 1.397 & 1.387 & 1.400 & 1.357 & 1.368 & 1.392 & 1.395 \\
\hline $\mathrm{C} 2^{\prime} \mathrm{C} 3^{\prime}$ & 1.397 & 1.412 & 1.415 & 1.428 & 1.433 & 1.449 & 1.417 & 1.435 & 1.399 & 1.412 \\
\hline $\mathrm{C}^{\prime} \mathrm{C}^{\prime}$ & 1.391 & 1.391 & 1.383 & 1.389 & 1.369 & 1.375 & 1.382 & 1.390 & 1.390 & 1.391 \\
\hline $\mathrm{C}^{\prime} \mathrm{C} 5^{\prime}$ & 1.391 & 1.393 & 1.398 & 1.398 & 1.417 & 1.417 & 1.397 & 1.391 & 1.392 & 1.394 \\
\hline $\mathrm{C}^{\prime} \mathrm{C} 6^{\prime}$ & 1.392 & 1.396 & 1.384 & 1.397 & 1.366 & 1.375 & 1.390 & 1.403 & 1.392 & 1.395 \\
\hline $\mathrm{C} 3 \mathrm{C} 3^{\prime}$ & - & 1.463 & - & 1.461 & - & 1.451 & - & 1.442 & - & 1.463 \\
\hline $\mathrm{C} 2 \mathrm{C} 7 \mathrm{C} 2^{\prime}$ & 109.0 & 101.8 & 122.8 & 106.9 & 121.7 & 105.9 & 129.1 & 106.5 & 112.1 & 102.4 \\
\hline C2N1C6 & 119.3 & 116.7 & 120.9 & 115.8 & 120.5 & 116.1 & 124.9 & 122.3 & 118.1 & 116.2 \\
\hline $\mathrm{C} 2^{\prime} \mathrm{N} 1^{\prime} \mathrm{C} 6^{\prime}$ & 118.2 & 116.1 & 120.9 & 115.8 & 124.9 & 121.4 & 118.7 & 116.0 & 118.1 & 116.2 \\
\hline $\mathrm{C} 2 \mathrm{C} 7 \mathrm{C} 8$ & 116.6 & 113.3 & 118.6 & 126.5 & 120.2 & 129.8 & - & - & - & - \\
\hline $\mathrm{C} 2^{\prime} \mathrm{C} 7 \mathrm{C} 8$ & 111.1 & 116.9 & 118.6 & 126.5 & 118.1 & 124.3 & - & - & - & - \\
\hline $\mathrm{N} 1 \mathrm{C} 2 \mathrm{C} 7 \mathrm{C} 8$ & 37.0 & -52.0 & 19.8 & 0.0 & 28.0 & 0.0 & - & - & - & - \\
\hline $\mathrm{N} 1^{\prime} \mathrm{C} 2{ }^{\prime} \mathrm{C} 7 \mathrm{C} 8$ & 145.2 & 58.8 & 19.8 & 0.0 & 12.2 & 0.0 & - & - & - & - \\
\hline $\mathrm{N} 1 \mathrm{C} 2 \mathrm{C} 7 \mathrm{C} 2^{\prime}$ & -89.8 & 178.3 & -160.2 & 180.0 & -152.1 & 180.0 & 180.0 & 180.0 & -95.8 & 180.0 \\
\hline $\mathrm{N} 1{ }^{\prime} \mathrm{C} 2^{\prime} \mathrm{C} 7 \mathrm{C} 2$ & -85.0 & -177.3 & -160.2 & 180.0 & -167.7 & 180.0 & 0.0 & 180.0 & -95.8 & 180.0 \\
\hline
\end{tabular}

energy increase along the interring torsional motions, prevent the $\mathrm{H} 9$ and $\mathrm{N} 1$ atoms to approach each other as close as in 1a. This results in elongation (weakening) of the $\mathrm{H} \cdots \mathrm{N} 1$ hydrogen bond $(1.918 \AA$ in $\mathbf{1 b} v s$. $1.738 \AA$ in 1a) and shortening (strengthening) of the $\mathrm{O} 9 \mathrm{H}$ bond. The carbon-nitrogen bond lengths in the pyridine rings of $\mathbf{1 a}$ and $\mathbf{1 b}$ are close to these in pyridine itself $(1.337 \AA$; geometry optimized at the B3LYP/6-311G** level). The same applies to the ring carbon-carbon bond lengths which are comparable to the average bond length in pyridine (1.393 $\AA$ ). Slight elongation of the carbon-nitrogen bonds in $\mathbf{1 a}$ and $\mathbf{1 b}$ is observed for the ring involved in the hydrogen bonding. The valence $\mathrm{CNC}$ angles in these systems are also comparable to those found in the molecule of pyridine $\left(117.2^{\circ}\right)$.

2. Formation of the $\mathrm{H}^{\cdots} \cdot \mathrm{N} 1$ and $\mathrm{H} \cdots \mathrm{N} 1^{\prime}$ hydrogen bonds in $\mathbf{2 a}$ and $\mathbf{2 b}$ affects the hybridization of $\mathrm{C} 7$ and shortens the C7C8 bond lengths (1.419 $\AA$ in $\mathbf{2 a}$ and $1.376 \AA$ in $\mathbf{2 b})$ as compared to these in $\mathbf{1 a}$ and $\mathbf{1 b}$. These bonds resemble more the carbon-carbon bonds in the benzene ring $(\sim 1.39 \AA)$ rather than those in alkenes $(\sim 1.33 \AA)$. It should be noted that $\mathrm{C} 7 \mathrm{C} 8$ bond in $\mathbf{2 a}$ is longer, while this in $\mathbf{2 b}$ is shorter than $1.39 \AA$. Effective electron delocalization in the quasi rings that involve $\mathrm{OH} \cdots \mathrm{N}$ fragments results also in shortening of the $\mathrm{C} 7 \mathrm{C} 2$ and C7C2' bonds both in $\mathbf{2} \mathbf{a}$ and $\mathbf{2} \mathbf{b}$ (they are still significantly longer than the aromatic carbon-carbon 
Table 2 Selected optimized (B3LYP/6-311G**) bond lengths $[\AA]$ as well as valence and torsion angles [deg] in the transition states

\begin{tabular}{|c|c|c|c|c|c|c|c|c|}
\hline Bond/angle & TS1a & TS1b & $\mathrm{TS} 2 \mathrm{a}$ & $\mathrm{TS} 2 \mathrm{~b}$ & TS3a & $\mathrm{TS} 3 \mathrm{~b}$ & TS4a & TS4b \\
\hline O9H9 & 1.009 & 0.984 & 0.994 & 0.982 & 1.829 & 1.549 & - & - \\
\hline N1H9 & 1.754 & 2.078 & 1.721 & 1.883 & 1.030 & 1.093 & 1.263 & 1.356 \\
\hline $\mathrm{O} 10 \mathrm{H} 7$ & 1.246 & 1.345 & 2.881 & 2.861 & - & - & - & - \\
\hline N1'H7 & 2.829 & 2.596 & 1.271 & 1.358 & - & - & - & - \\
\hline $\mathrm{C} 8 \mathrm{O} 10$ & 1.265 & 1.260 & 1.216 & 1.208 & 1.192 & 1.204 & - & - \\
\hline C8O9 & 1.290 & 1.307 & 1.338 & 1.350 & 1.221 & 1.262 & - & - \\
\hline $\mathrm{C} 7 \mathrm{H} 7$ & 1.526 & 1.455 & 1.583 & 2.115 & 1.085 & 1.093 & 1.091 & 1.086 \\
\hline C7H9 & 2.459 & 2.464 & 1.362 & 2.355 & - & - & 1.608 & 1.609 \\
\hline $\mathrm{C} 7 \mathrm{C} 2$ & 1.485 & 1.456 & 1.463 & 1.417 & 1.432 & 1.464 & 1.467 & 1.435 \\
\hline $\mathrm{C} 7 \mathrm{C} 2^{\prime}$ & 1.493 & 1.488 & 1.490 & 1.434 & 1.492 & 1.499 & 1.455 & 1.460 \\
\hline $\mathrm{C} 7 \mathrm{C} 8$ & 1.489 & 1.452 & 1.495 & 1.475 & 1.951 & 1.692 & - & - \\
\hline $\mathrm{N} 1 \mathrm{C} 2$ & 1.354 & 1.336 & 1.354 & 1.357 & 1.371 & 1.335 & 1.359 & 1.343 \\
\hline N1C6 & 1.337 & 1.342 & 1.335 & 1.322 & 1.356 & 1.351 & 1.343 & 1.338 \\
\hline $\mathrm{N} 1^{\prime} \mathrm{C} 2^{\prime}$ & 1.345 & 1.328 & 1.351 & 1.427 & 1.345 & 1.327 & 1.353 & 1.341 \\
\hline $\mathrm{N} 1{ }^{\prime} \mathrm{C} 6^{\prime}$ & 1.335 & 1.338 & 1.341 & 1.344 & 1.333 & 1.339 & 1.335 & 1.331 \\
\hline $\mathrm{C} 2 \mathrm{C} 3$ & 1.403 & 1.418 & 1.413 & 1.437 & 1.416 & 1.411 & 1.399 & 1.411 \\
\hline $\mathrm{C} 3 \mathrm{C} 4$ & 1.387 & 1.391 & 1.384 & 1.403 & 1.374 & 1.388 & 1.387 & 1.399 \\
\hline $\mathrm{C} 4 \mathrm{C} 5$ & 1.395 & 1.396 & 1.397 & 1.381 & 1.414 & 1.406 & 1.405 & 1.401 \\
\hline $\mathrm{C} 5 \mathrm{C} 6$ & 1.388 & 1.396 & 1.387 & 1.415 & 1.367 & 1.383 & 1.384 & 1.403 \\
\hline $\mathrm{C} 2^{\prime} \mathrm{C} 3^{\prime}$ & 1.407 & 1.427 & 1.390 & 1.483 & 1.405 & 1.422 & 1.413 & 1.444 \\
\hline $\mathrm{C}^{\prime} \mathrm{C}^{\prime}$ & 1.386 & 1.391 & 1.392 & 1.382 & 1.388 & 1.391 & 1.383 & 1.394 \\
\hline $\mathrm{C}^{\prime} \mathrm{C} 5^{\prime}$ & 1.395 & 1.392 & 1.399 & 1.400 & 1.392 & 1.392 & 1.398 & 1.388 \\
\hline $\mathrm{C}^{\prime} \mathrm{C} 6^{\prime}$ & 1.390 & 1.398 & 1.386 & 1.394 & 1.392 & 1.398 & 1.390 & 1.404 \\
\hline C3C $3^{\prime}$ & - & 1.455 & - & 1.420 & - & 1.460 & - & 1.452 \\
\hline $\mathrm{C} 2 \mathrm{C} 7 \mathrm{C} 2^{\prime}$ & 117.8 & 104.6 & 119.9 & 105.4 & 122.7 & 101.4 & 121.3 & 102.0 \\
\hline C2N1C6 & 119.7 & 116.0 & 119.9 & 116.7 & 124.1 & 120.8 & 123.3 & 118.4 \\
\hline $\mathrm{C} 2^{\prime} \mathrm{N} 1^{\prime} \mathrm{C} 6^{\prime}$ & 118.9 & 116.2 & 123.1 & 115.6 & 118.8 & 116.2 & 118.5 & 116.5 \\
\hline $\mathrm{C} 2 \mathrm{C} 7 \mathrm{C} 8$ & 113.7 & 121.0 & 123.1 & 127.0 & 104.2 & 107.7 & - & - \\
\hline $\mathrm{C} 2^{\prime} \mathrm{C} 7 \mathrm{C} 8$ & 112.3 & 127.7 & 111.0 & 127.2 & 101.7 & 122.7 & - & - \\
\hline $\mathrm{N} 1 \mathrm{C} 2 \mathrm{C} 7 \mathrm{C} 8$ & -30.2 & 10.3 & 23.2 & -5.2 & 54.7 & -41.3 & - & - \\
\hline $\mathrm{N} 1{ }^{\prime} \mathrm{C} 2^{\prime} \mathrm{C} 7 \mathrm{C} 8$ & -1.7 & -22.8 & -95.8 & 13.2 & 104.5 & 62.8 & - & - \\
\hline $\mathrm{N} 1 \mathrm{C} 2 \mathrm{C} 7 \mathrm{C} 2^{\prime}$ & 104.3 & 163.7 & 173.6 & -178.8 & -59.6 & -171.3 & 138.3 & -157.3 \\
\hline $\mathrm{N} 1{ }^{\prime} \mathrm{C} 2{ }^{\prime} \mathrm{C} 7 \mathrm{C} 2$ & -136.7 & -173.7 & 110.5 & -173.2 & -139.9 & -177.4 & -12.6 & -176.9 \\
\hline
\end{tabular}

bonds) as compared to these in $\mathbf{1 a}$ and $\mathbf{1 b}$ (the $\mathrm{C} 7 \mathrm{C} 8$, $\mathrm{C} 7 \mathrm{C} 2$ and $\mathrm{C} 7 \mathrm{C} 2{ }^{\prime}$ bonds in their molecules are typical carbon-carbon single bonds). The H9O9 and the hydrogen $\mathrm{H}^{\cdots} \cdot \mathrm{N} 1^{(1)}$ bond lengths in $\mathbf{2 a , b}$ follow the same pattern as these in the molecules of $\mathbf{1 a}, \mathbf{b}$. Moreover, $\mathrm{C} 3 \mathrm{C} 3^{\prime}$ bond in $\mathbf{2} \mathbf{b}$ is much longer than $\mathrm{C} 7 \mathrm{C} 2^{(\prime)}$ and $\mathrm{C} 2^{(\prime)} \mathrm{C}^{\left({ }^{\prime \prime}\right)}$ bonds (which have comparable lengths, $c f$. Table 1). Thus, aromaticity of the five membered ring in $\mathbf{2 b}$ is doubtful what negates stabilization of this form by resonance suggested in Fig. 3.

3. The $\mathrm{NH} \cdots \mathrm{O}$ hydrogen bonds are present in the enaminone tautomeric forms $\mathbf{3} \mathbf{a}$ and $\mathbf{3} \mathbf{b}$ (these bonds are longer than the $\mathrm{OH}^{\cdots} \mathrm{N}$ hydrogen bonds in $\mathbf{2 a}$ and 2b). Contribution of the zwitterionic structures of $\mathbf{3}$ ( $c f$. Figure 5) is manifested in shortening of the $\mathrm{C} 7 \mathrm{C} 8$ bonds (this effect is not as significant as for 2) and elongation of the $\mathrm{C} 8 \mathrm{O} 10$ bonds as compared to $\mathbf{1}$.

4. 4a and $\mathbf{4 b}$ seem likely to be the intermediate products of decarboxylation of $\mathbf{1 a}$ and $\mathbf{1 b}$, respectively. Both these molecules are planar. Hydrogen atom involved in the $\mathrm{H} \cdots \mathrm{N} 1$ hydrogen bonding in $\mathbf{1 a}$ and $\mathbf{1 b}$ is bound to $\mathrm{N} 1$. The N1H bond lengths (1.009 $\AA$ in both systems) are in between these found for pyrrole $(1.006 \AA)$ and aliphatic amines $(1.015 \AA$; geometry optimized at the B3LYP/6-311G** level). The C7C2 and C7C2' bond lengths are intermediate between these of the single and double carbon-carbon bonds. In both $\mathbf{4 a}$ and $\mathbf{4 b}$ the 
$\mathrm{C} 7 \mathrm{C} 2$ bonds are shorter, while $\mathrm{C} 7 \mathrm{C} 2$ ' are longer than $1.39 \AA$ (Table 1).

5. 5a and $\mathbf{5 b}$ are probably the final products of decarboxylation of $\mathbf{1 a}$ and $\mathbf{1 b}$. Their geometrical parameters remain similar to these found for $\mathbf{1 a}$ and $\mathbf{1 b}$, as well as those in pyridine itself. Note that the pyridine rings in $\mathbf{5 b}$ are coplanar.

Reaction paths and energetic effects

Calculations of the energetic effects of the most intuitive reactions $\mathbf{1} \rightarrow \mathbf{5}+\mathrm{CO}_{2}$ reveal that products are by $c a .13 .6$ (case a) and $c a .15 .8 \mathrm{kcalmol}^{-1}$ (case b) more stable than substrates. All energetic effects $\left|E_{\text {products }}-E_{\text {substrates }}\right|$ and energy barriers $\mathrm{E}_{\mathrm{TS}}-\mathrm{E}_{\text {substrates/products }}$ discussed (denoted as $\Delta \mathrm{E})$ were corrected for the zero-point energy, ZPE. They are depicted in Fig. 9. The data used in order to obtain these values (i.e., total energies of the molecules and $\mathrm{ZPE}$ corrections of all stable structures and transition states) are reported in Table 3. Note that for the brevity reason the $\Delta \mathrm{G}$ values were calculated for decarboxylation processes only. Comparable entropies of the substrates and products for the tautomerization processes suggest that the $\Delta \mathrm{E}$ and $\Delta \mathrm{G}$ values also approximate each other.

Ene-1,1-diols 2 have lower energies than the respective acids 1: the energy lowering is equal to approximately 0.7 and $7 \mathrm{kcalmol}^{-1}$ for $\mathbf{2 a}$ and $\mathbf{2 b}$, respectively (Fig. 9). The energy barriers for the proton migration from $\mathrm{C} 7$ toward the carbonyl oxygen atom $\mathrm{O} 10$ (this processes proceed via TS1 transition states) are nearly the same for $\mathbf{a}$ and $\mathbf{b}$ and amount to $c a$. $55 \mathrm{kcalmol}^{-1}$. The enaminone tautomeric forms 3a,b are thermodynamically somewhat more stable than $\mathbf{2 a , b}$ (by nearly $4 \mathrm{kcalmol}^{-1}$ in the case of $\mathbf{3 b}$ ). However, the energy barriers for the migration of proton $\mathrm{H} 7$ toward N1', associated with the presence of TS2a and TS2b transition states, differ significantly: the calculated $\Delta \mathrm{E}$ values are equal to $c a .44$ and $c a .62 \mathrm{kcalmol}^{-1}$ for $\mathbf{1 a} \rightarrow \mathbf{3 a}$ and $\mathbf{1 b} \rightarrow \mathbf{3 b}$, respectively. In a view of finding more energetically favorable processes from the thermody-
Fig. 9 Reaction paths, ZPE corrected energy barriers and energetic effects $(\Delta \mathrm{E}$ in $\mathrm{kcal}$ $\left.\mathrm{mol}^{-1}\right)$ in tautomerization and decarboxylation of $\mathbf{1 a}$ and $\mathbf{1 b}$. The calculated $\Delta \mathrm{G}$ values (for decarboxylation processes only) are reported in parentheses
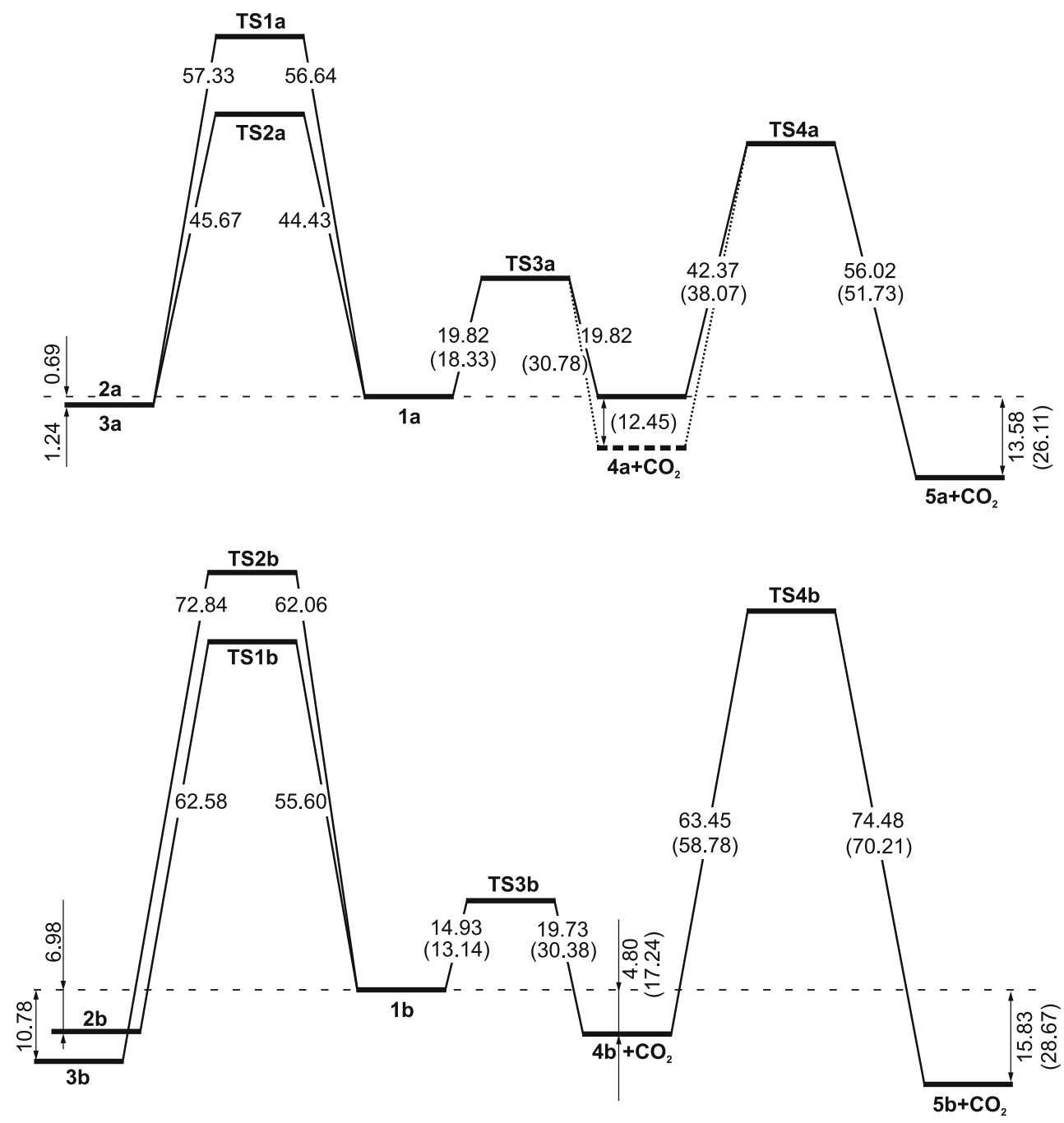
Table 3 Total energies (in a.u.) and ZPE corrections (in $\mathrm{kcalmol}^{-1}$ ) of the substrates, products and transition states

\begin{tabular}{|c|c|c|}
\hline & $\mathrm{E}$ & $\mathrm{ZPE}$ \\
\hline $2 \mathbf{a}$ & -723.447573 & 125.63 \\
\hline $3 \mathbf{a}$ & -723.449268 & 126.14 \\
\hline \multicolumn{3}{|l|}{$\uparrow$} \\
\hline TS1a & -723.350792 & 122.21 \\
\hline TS2a & -723.370685 & 122.49 \\
\hline \multicolumn{3}{|l|}{$\downarrow$} \\
\hline 1a & -723.447339 & 126.17 \\
\hline \multicolumn{3}{|l|}{$\downarrow$} \\
\hline TS3a & -723.413217 & 124.57 \\
\hline \multicolumn{3}{|l|}{$\downarrow$} \\
\hline $\mathbf{4 a}+\mathrm{CO}_{2}$ & -723.443569 & 123.81 \\
\hline \multicolumn{3}{|l|}{$\downarrow$} \\
\hline $\mathbf{T S} 4 \mathbf{a}+\mathrm{CO}_{2}$ & -723.369568 & 119.72 \\
\hline \multicolumn{3}{|l|}{$\downarrow$} \\
\hline $\mathbf{5 a}+\mathrm{CO}_{2}$ & -723.465199 & 123.80 \\
\hline $2 b$ & -722.252866 & 113.08 \\
\hline $3 \mathbf{b}$ & -722.259203 & 113.25 \\
\hline \multicolumn{3}{|l|}{$\uparrow$} \\
\hline TS1b & -722.146161 & 108.67 \\
\hline TS2b & -722.135826 & 108.65 \\
\hline \multicolumn{3}{|l|}{$\downarrow$} \\
\hline $1 b$ & -722.240663 & 112.39 \\
\hline \multicolumn{3}{|l|}{$\downarrow$} \\
\hline TS3b & -722.213498 & 110.27 \\
\hline \multicolumn{3}{|l|}{$\downarrow$} \\
\hline $\mathbf{4 b}+\mathrm{CO}_{2}$ & -722.245186 & 110.43 \\
\hline \multicolumn{3}{|l|}{$\downarrow$} \\
\hline $\mathbf{T S} 4 \mathbf{b}+\mathrm{CO}_{2}$ & -722.136557 & 105.69 \\
\hline \multicolumn{3}{|l|}{$\downarrow$} \\
\hline $\mathbf{5 b}+\mathrm{CO}_{2}$ & -722.262235 & 110.10 \\
\hline
\end{tabular}

namic and kinetic point of view (vide infra) we conclude that tautomerization of $\mathbf{1 a}$ and $\mathbf{1 b}$ is not likely to proceed. Among all investigated processes, namely $\mathbf{1} \rightarrow \mathbf{2}, \mathbf{1} \rightarrow \mathbf{3}$, and $\mathbf{1} \rightarrow \mathbf{5}+\mathrm{CO}_{2}$, the most distinct energetic effect can be seen for $\mathbf{1} \rightarrow \mathbf{5}+\mathrm{CO}_{2}$ (for both $\mathbf{a}$ and $\mathbf{b}$, cf. Fig. 9). These processes will be discussed in detail.

Rupture of the $\mathrm{C} 7 \mathrm{C} 8$ bond in the $\mathbf{1} \rightarrow \mathbf{4}+\mathrm{CO}_{2}$ reaction is probably followed by migration of the carboxylic hydrogen atom to $\mathrm{C} 7$ (this results in formation of 5). The concerted and step-wise mechanisms have to be considered here. In the first one, the eigenmode (atomic displacements) corresponding to the imaginary frequency should correspond to simultaneous detachment of $\mathrm{CO}_{2}$ and migration of the carboxylic proton $\mathrm{H} 9$ toward $\mathrm{C} 7$. The later mechanism is expected to involve a few different transition states. Case a will be considered first. A quick glance at the structure of 1a points at the second, i.e., step-wise mechanism. The reason for this is a significant energy increase when $\mathrm{H} 9$ approaches $\mathrm{C} 7$, while $\mathrm{C} 7$ is still bound to $\mathrm{C} 8$. It is shown in Fig. 10 as a steep, violet (turning to blue at larger values of $R$ ) "slope" on a cross-section of the potential energy hypersurface of 1a. In addition, elongation of the C7C8 bond reveals that there is a clear trend for the $\mathrm{H} 9$ atom to approach N1, i.e., to form $4 \mathbf{a}$. Therefore one should search for a transition state that appears in the course of reaction $\mathbf{1 a} \rightarrow \mathbf{T S 3 a} \rightarrow \mathbf{4 a}+\mathrm{CO}_{2}$. It was found to be nearly $20 \mathrm{kcal}$ $\mathrm{mol}^{-1}$ above 1a. The calculated $\Delta \mathrm{G}$ value corresponding to the reported $\Delta \mathrm{E}$ amounts to $18.33 \mathrm{kcalmol}^{-1}$. This value is known to be low enough for the process that is fast under standard conditions. Analysis of geometrical parameters shows that C7C8 bond in TS3a is significantly longer than that in 1a, and that the $\mathrm{H}^{\cdots} \mathrm{N} 1$ bond remains close to that of 4a ( $c f$. Tables 1 and 2). The structure of TS3a is depicted in Fig. 11 (the eigenmode, corresponding to the imaginary frequency equal to $i 320 \mathrm{~cm}^{-1}$, is also shown there). Following the reaction path from TS3a along the intrinsic reaction coordinate (IRC), $\mathbf{1 a}$ or $\mathbf{4 a}+\mathrm{CO}_{2}$ were obtained. No energy lowering is observed at this stage of decarboxylation. However, value of the Gibbs free energy of the products calculated at $298 \mathrm{~K}$ is by more than $12 \mathrm{kcalmol}^{-1}$ lower than that of 1a. Although rotational and vibrational entropies were also changed $\left(\Delta \mathrm{S}_{\mathrm{rot}}=11.9 \mathrm{calmol}^{-1} \mathrm{~K}^{-1}\right.$ and $\Delta \mathrm{S}_{\mathrm{vib}}=$ $\left.-12.2 \mathrm{calmol}^{-1} \mathrm{~K}^{-1}\right)$, significant increase in the translational entropy $\left(\Delta \mathrm{S}_{\text {trans }}=36.6 \mathrm{calmol}^{-1} \mathrm{~K}^{-1}\right)$ gives the major contribution to the reported value of $\Delta \mathrm{G}$. The low energy barrier being $<20 \mathrm{kcalmol}^{-1}$ (corresponding to energy of quanta in the near IR region) as well as negative value of $\Delta \mathrm{G}$ clearly show that 1a decomposes spontaneously (and rapidly) to form 4a and $\mathrm{CO}_{2}$. This proves that Eistert and Schade [10] could not obtain 1a. It is probably why we were not able to obtain this compound starting from 2-diazo-1,2-di(pyridin2-yl)ethanone [10] as well as by hydrolysis of 2,2-di (pyridin-2-yl)acetonitrile (the standard procedure).

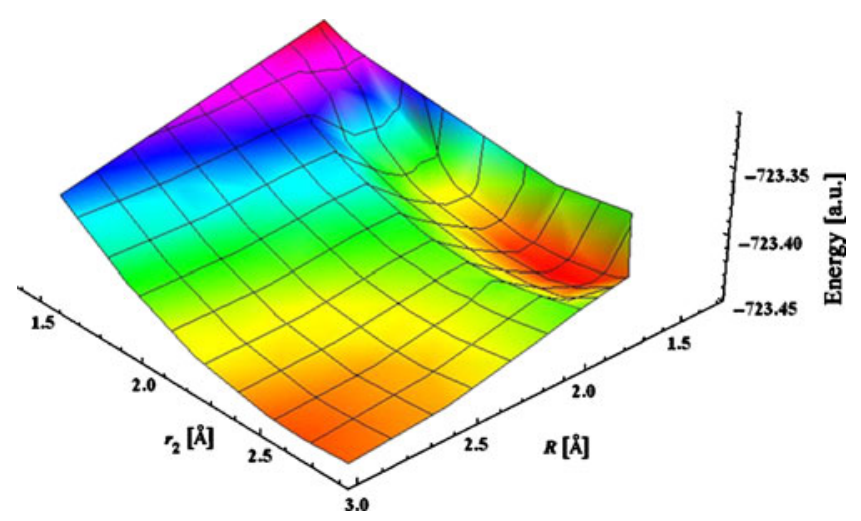

Fig. 10 Cross-section of the potential energy surface (PES) of 1a corresponding to the rupture of $\mathrm{C} 7 \mathrm{C} 8$ (variable $R$ ) bond and simultaneous migration of the hydroxyl proton toward C7 (variable $r_{2}$ ) 
Fig. 11 Transition states TS3a and TS4a. The arrows show the atomic displacement corresponding to the imaginary frequencies

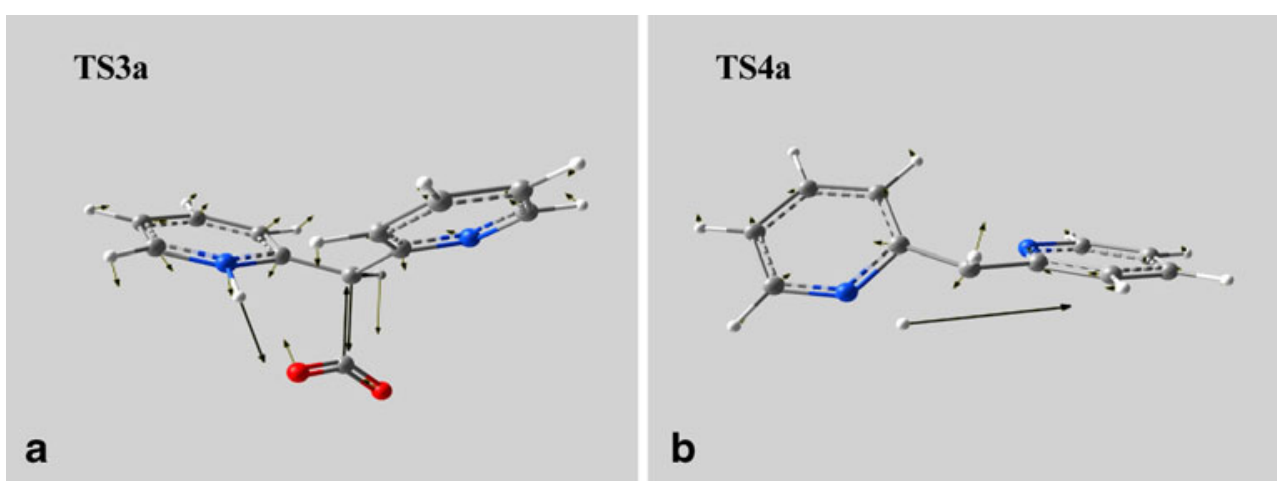

4a is probably an intermediate in the process of decarboxylation of 1a. In order to obtain 5a, which is the most stable system studied (at least at the B3LYP level, $c f$. Fig. 9 and Table 3), the C7H9 bond has to be formed and, at the same time, the N1H9 bond has to be broken. It was not clear to us which is the mechanism of this step (i.e., unimolecular or bimolecular). It was initially assumed that the rearrangement takes place within the single molecule. This process is accompanied by breaking of the planar symmetry of $\mathbf{4 a}$ (note that $\mathrm{C} 7$ atom has to change its hybridization from $s p^{2}$ in $\mathbf{4 a}$ to $s p^{3}$ in $\mathbf{5 a}$ ). The search for another transition state (TS4a) was carried out in the way described in Sect. 2. Its structure along with the imaginary eigenmode $\left(i 1834 \mathrm{~cm}^{-1}\right)$ is shown in Fig. 11. Location of $\mathrm{H} 9$ more or less half way between N1 and C7 (cf. Table 2) is the characteristic feature of this transition state. The energy barrier $\Delta \mathrm{E}=42.37 \mathrm{kcalmol}^{-1}$ that has to be overstepped, corresponds to $\Delta \mathrm{G}$ value of $\mathrm{ca} .38 \mathrm{kcalmol}^{-1}$. It is two times higher than that for the $\mathrm{CO}_{2}$ detachment. This seems to be mostly due to the high strain within the 4-membered ring formed in the TS4a transition state. Thus, this step of the decarboxylation process, though spontaneous from the thermodynamic point of view, is expected to be much slower than the former one.

An alternative mechanism involves two molecules of $\mathbf{4 a}$. The B3LYP calculations show, that they are capable of forming a relatively stable dimer possessing the $\mathrm{C}_{2}$ symmetry. It is depicted on Fig. 12a; the binding energy, counterpoise (CP) corrected for the basis set superposition error [28] and ZPE corrected, is equal to $4.26 \mathrm{kcalmol}^{-1}$. The transition state, corresponding to the imaginary frequency of $i 1281 \mathrm{~cm}^{-1}$, was found to be only $14.58 \mathrm{kcal}$ $\mathrm{mol}^{-1}$ above the dimer (the ZPE corrected value; the corresponding $\Delta \mathrm{G}$ value is $\left.11.41 \mathrm{kcalmol}^{-1}\right)$. Analysis of the imaginary eigenmode shows that this is the transition state for the migration of the $\mathrm{H} 9$ atom from $\mathrm{N} 1$ atom of one 4a molecule to the $\mathrm{C} 7$ atom of the other $\mathbf{4 a}$ molecule (actually, two molecules of 5a were finally obtained by following the reaction path along the intrinsic reaction coordinate). The B3LYP energetic effect of the overall reaction, i.e., $(\mathbf{4 a})_{2} \rightarrow 2 \mathbf{5 a}$, is $10.85 \mathrm{kcalmol}^{-1}$ per molecule $\left(\Delta \mathrm{G}=17.14 \mathrm{kcalmol}^{-1}\right)$. However, it should be noted that the dimer predicted by B3LYP calculations is stabilized by the interactions of the $\mathrm{NH}$ fragment of one molecule (a rather weak dipole) with the non-polar $\mathrm{C}^{\cdots} \mathrm{C} \cdots \mathrm{C}$ system of the other molecule (the quadrupole, $c f$. Fig. 12a). Thus, the

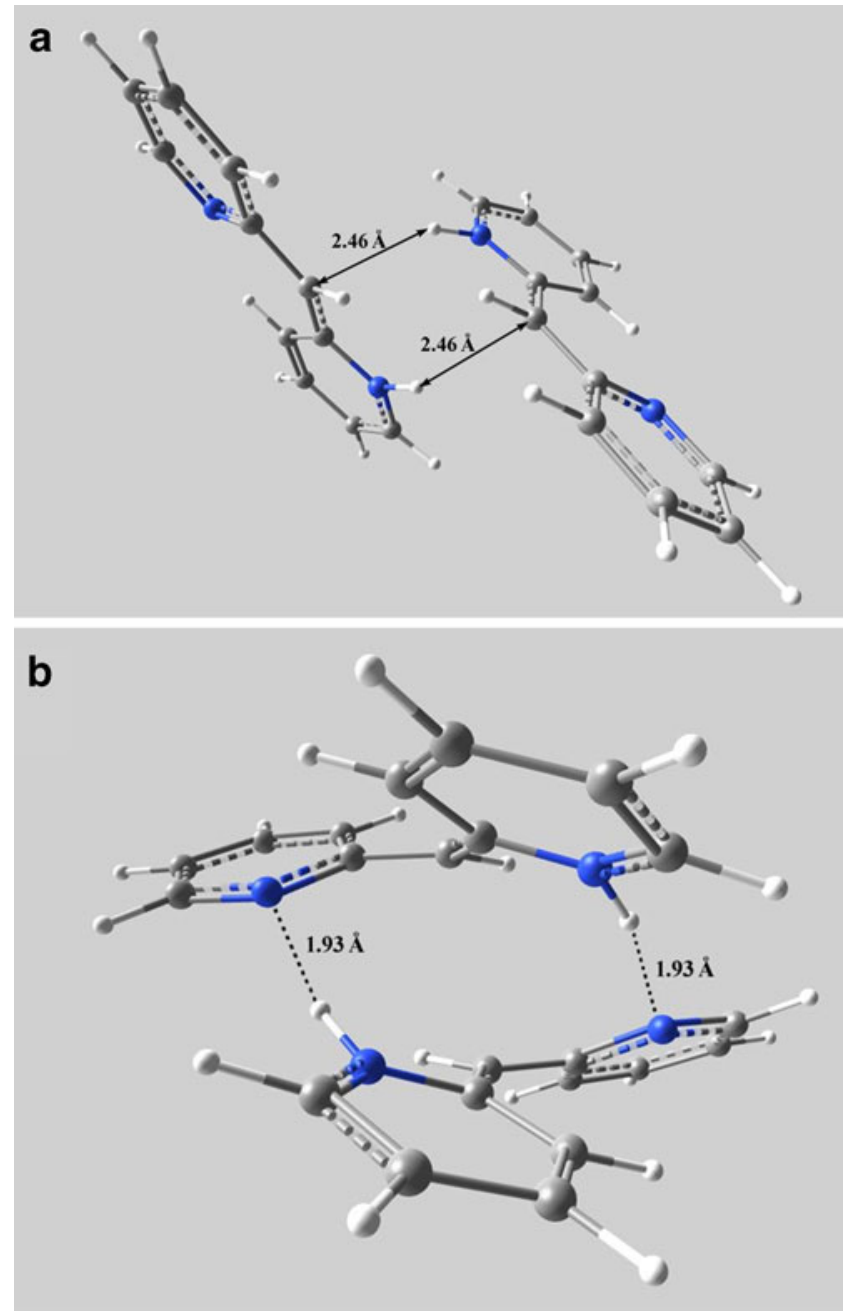

Fig. 12 The dimers of $\mathbf{4 a}$ predicted at (a) B3LYP and (b) MP2 levels 
Fig. 13 Transition states TS3b and TS4b. The arrows show the atomic displacement corresponding to the imaginary frequencies

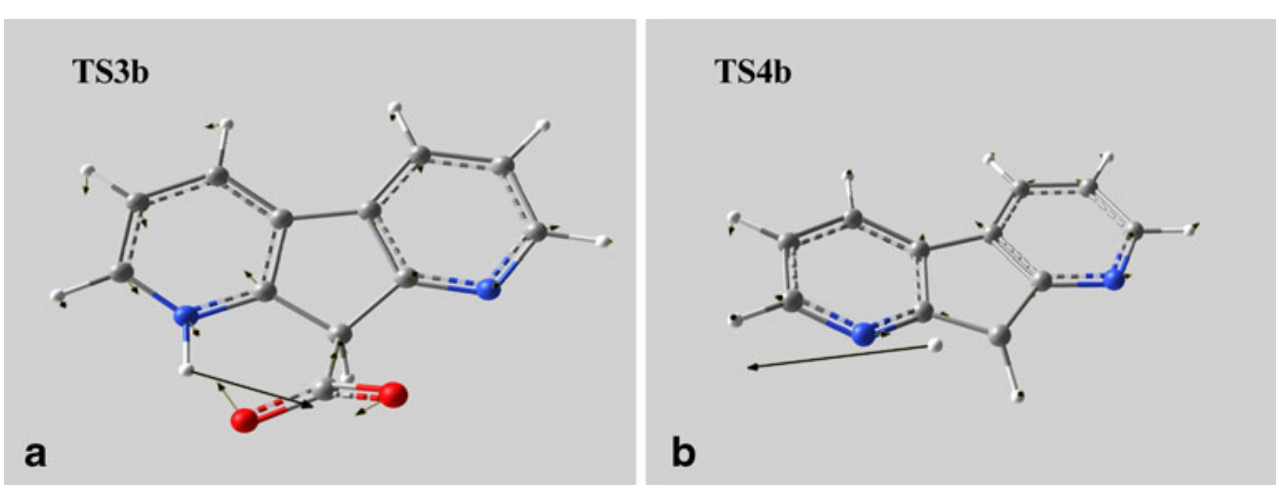

dispersive-type interactions that show the $U_{\mathrm{disp}} \sim r^{-6}$ dependence on distance, are not negligible as compared to the weak electrostatic dipole-quadrupole interactions $U_{\text {dip-quad }} \sim$ $r^{-4}$. The same type of interactions are expected in the transition state. Since DFT is known to poorly describe the dispersive interactions, we decided to investigate this problem using the MP2 method with the same basis set. The geometry optimization of the dimer of $\mathbf{4 a}$ was carried out at the MP2/6-311G** level, using the B3LYP structure as an initial guess. This time we did not obtain the analogous dimer; two $\mathrm{NH}^{\cdots} \mathrm{N}$ hydrogen bonds were formed instead. This complex, for which the CP corrected binding energy is $14.29 \mathrm{kcalmol}^{-1}$ (the MP2 frequencies were not calculated for practical reasons, but the ZPE estimate obtained at the DFT level, would further reduce this value by $c a .0 .7 \mathrm{kcalmol}^{-1}$ ), is shown in Fig. 12b. Thus it seems, that the DFT calculations overestimate the dispersive interactions when two molecules of $4 \mathbf{a}$ approach each other.

In a view of the MP2 results we conclude that the unimolecular mechanism is responsible for the formation of 5a. Note that the $\mathrm{NH}^{-\cdots \mathrm{N}}$ links are typically responsible for the chemical exchange of the labile protons. Actually, compounds 4a and 5a were obtained by following the reaction path from TS4a along the intrinsic reaction coordinate. It should be noted that the reported energy barrier of $c a .40 \mathrm{kcalmol}^{-1}$ is comparable to that found for the $\mathbf{1 a} \rightarrow \mathbf{T S 2 a} \rightarrow \mathbf{3 a}$ reaction. However, low energy barrier of the $\mathrm{CO}_{2}$ detachment, and significantly higher stability of $\mathbf{5 a}$ as compared to $\mathbf{3 a}$, proves that synthesis of 1a [10] could not be successful: this compound spontaneously decarboxylates when it is formed.

Structures of the TS3b and TS4b transition states in decarboxylation of $\mathbf{1 b}$ as well as imaginary eigenmodes (corresponding to frequencies equal to $i 332 \mathrm{~cm}^{-1}$ and $i 2050 \mathrm{~cm}^{-1}$, respectively) are depicted in Fig. 13. Weaker intramolecular hydrogen bond in $\mathbf{1 b}$ as compared to that in 1a (cf. Table 1), is to some extent responsible for the lower energy barrier $\left(\Delta \mathrm{G} \approx 13 \mathrm{kcalmol}^{-1}\right.$, cf. Fig. 9) of the dissociation process $\mathbf{1 b} \rightarrow \mathbf{4} \mathbf{b}+\mathrm{CO}_{2}$, and for the formation of the $\mathrm{N} 1 \mathrm{H}$ bond in $\mathbf{4 b}$. This stage of the reaction is expected to be spontaneous as well: energy lowering $(\Delta \mathrm{E}=$ $4.8 \mathrm{kcalmol}^{-1}$, and $\Delta \mathrm{G}=17.24 \mathrm{kcalmol}^{-1}$ ) was observed. The most significant difference between this (b) and previous (a) decarboxylation processes is an increase of the energy barrier associated with the migration of $\mathrm{H} 9$ toward $\mathrm{C} 7$ in the $\mathbf{4 b} \rightarrow \mathbf{5 b}$ tautomerization by more than $20 \mathrm{kcalmol}^{-1}$. This value refers to both $\Delta \mathrm{E}$ and $\Delta \mathrm{G}$. Note, that we assume the unimolecular mechanism of tautomerization, in spite of finding a relatively stable dimer of $\mathbf{4 b}$ at the B3LYP level, analogous to the dimer of $\mathbf{4 a}$, for which the $\mathrm{CP}$ corrected binding energy is equal to $c a .6 \mathrm{kcalmol}^{-1}$ (the imaginary eigenmode for the transition state found for $(\mathbf{4 b})_{2} \rightarrow 2 \mathbf{5 b}$ reaction corresponds to $i 1149 \mathrm{~cm}^{-1}$, the $\Delta \mathrm{E} /$ $\Delta \mathrm{G}$ energy barriers are $c a .14 .7 / 12.6 \mathrm{kcalmol}^{-1}$, and the $\Delta \mathrm{E} / \Delta \mathrm{G}$ energetic effects are ca. 7.5/13.6 $\mathrm{kcalmol}^{-1}$ per molecule, respectively). However, this time the lengthy MP2 calculations were not carried out. The reason for this can be easily understood when structures involved in the described processes are analyzed. The change in the hybridization of $\mathrm{C} 7$ to $s p^{3}$ when going from $\mathbf{4 b}$ to $\mathbf{5 b}$ via TS4b is associated with breaking of the planar symmetry of 4b. Similar behavior is also observed in reaction $\mathbf{4 a} \rightarrow \mathbf{5 a}$. One should keep in mind, however, that the $\mathrm{C} 3 \mathrm{C} 3^{\prime}$ bond

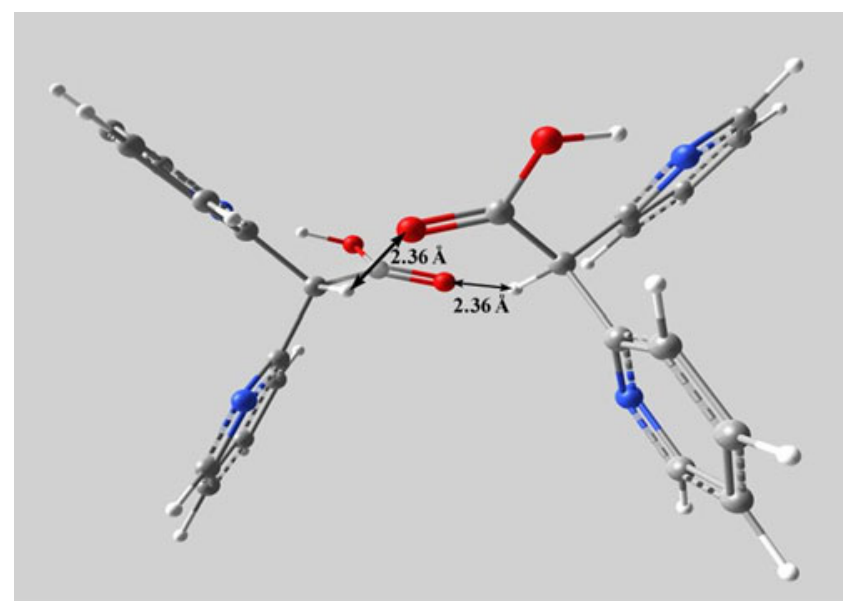

Fig. 14 The dimer of 1a predicted at B3LYP level 
makes the molecules $\mathbf{4 b}$ and $\mathbf{5 b}$ rigid (cf. Sect. 3.1), and this results in a steeper energy increase under torsional distortions. As a consequence, significantly risen energy barrier of the $\mathbf{4 b} \rightarrow \mathbf{5 b}$ step ( $c a .60 \mathrm{kcalmol}^{-1}$ ) may preclude tautomerization to proceed. Thus, $\mathbf{4 b}$ may appear to be the final product of decarboxylation of $\mathbf{1} \mathbf{b}$. In addition, it can be seen from Fig. 9 and Table 3 that although $\mathbf{5 b}$ is thermodynamically more stable than $\mathbf{5 a}$, kinetic control of the $\mathbf{4 a} \rightarrow \mathbf{5 a}$ process is more distinct than that of $\mathbf{4 b} \rightarrow \mathbf{5 b}$.

Finally we would like to point out that the bimolecular mechanism was also considered in the case of the enolization process of 1a. The stable dimer, that could initiate the $\mathrm{H}$ proton transfer from $\mathrm{C} 7$ atom of one molecule of $1 \mathbf{a}$ to $\mathrm{O} 10$ atom of the other molecule of $\mathbf{1 a}$, was found at the B3LYP level. It is shown in Fig. 14. This time no transition state associated with such a migration was found (the MP2 calculations were not carried out).

\section{Conclusions}

Tautomerization and decarboxylation of 2,2-di(pyridin-2yl)acetic acid were considered to be responsible for its instability. DFT/B3LYP/6-311G** calculations show that the products of decarboxylation of this acid and its rigid cyclic analogue, 1,8-diazafluorene-9-carboxylic acid, are more energetically favorable than the corresponding ene1,1-diols (products of migration of the methine proton toward the carbonyl oxygen atom) and enaminones (products of migration of the same proton toward the pyridine nitrogen atom). The later tautomers were found to be thermodynamically more stable than enediols. Aromatization of the five membered ring has no effect on stabilization of ene-1,1-diol of 1,8-diazafluorene-9-carboxylic acid. Detachment of $\mathrm{CO}_{2}$ from 2,2-di(pyridin-2-yl)acetic and 1,8-diazafluorene-9-carboxylic acids to give $(E)$-2-(pyridin$2(1 H)$-ylidenemethyl)pyridine and its cyclic analogue, respectively, may be followed by tautomerization of these by-products into (dipyridin-2-yl)methane and 1,8-diazafluorene. The calculated energy barriers for the $\mathrm{CO}_{2}$ detachment correspond to quanta of IR radiation, so they can be easily overstepped in the course of reactions expected to afford 2,2-di(pyridin-2-yl)acetic and 1,8-diazafluorene-9carboxylic acids. Thus, spontaneous decarboxylation of the former is in line with the unsuccessful synthetic efforts.

Despite their instability, the labile compounds may appear as the intermediates in numerous (bio)chemical processes. Conclusions of the present paper may be valid also for other substituted acetic acids (and their homologues) that carry electronegative heteroatoms in the gamma positions, such as diacylacetic acids and their derivatives (to be also known as unstable compounds).

Open Access This article is distributed under the terms of the Creative Commons Attribution Noncommercial License which permits any noncommercial use, distribution, and reproduction in any medium, provided the original author(s) and source are credited.

\section{References}

1. Frey J, Rappoport Z (1996) J Am Chem Soc 118:5169-5181

2. Allen BM, Hegarty AF, O'Neill P, Nguyen MT (1992) J Chem Soc Perkin Trans 2:927-934

3. O'Neill P, Hegarty AF (1987) J Chem Soc Chem Commun 744-745

4. Allen BM, Hegarty AF, O'Neill P (1997) J Chem Soc Perkin Trans 2:2733-2736

5. Urwyler B, Wirz J (1990) Angew Chem Int Ed Engl 29:790-792

6. Gilli G, Belluci F, Ferretti V, Bertolasi V (1989) J Am Chem Soc 111:1023-1028

7. Bertolasi V, Gilli P, Ferretti V, Gilli G (1991) J Am Chem Soc 113:4917-4925

8. Gilli P, Bertolasi V, Ferretti V, Gilli G (1994) J Am Chem Soc 116:909-915

9. Bertolasi V, Gilli P, Ferretti V, Gilli G (1996) Chem Eur J 2:925-934

10. Eistert B, Schade W (1958) Chem Ber 91:1411-1415

11. Taylor PJ (1972) J Chem Soc Perkin Trans 2:1077-1086

12. Sicinska D, Lewandowicz A, Vokal B, Paneth P (2001) J Org Chem 66:5534-5536

13. Katritzky AR, Pozharsky AF (2000) Handbook of Heterocyclic Chemistry, 2nd edn. Pergamon, Elsevier, Amsterdam

14. von Doering WE, Pasternak VZ (1950) J Am Chem Soc 72:143-147

15. Sicinska D, Truhlar DG, Paneth P (2001) J Am Chem Soc 123:7683-7686

16. Headley GW, O’Leary MH (1990) J Am Chem Soc 112:1894-1896

17. Marlier JF, O'Leary MH (1986) J Am Chem Soc 108:4896-4899

18. Panizzon L (1944) Helv Chim Acta 27:1748-1756

19. O'Leary MH (1988) Acc Chem Res 21:450-455, and papers cited therein

20. British Patents $1,099,389 ; 1,121,922 ; 1.139,940 ; 1,147,068$ and $1,164,510$.

21. Parr RG, Yang W (1989) Density-Functional Theory of Atoms and Molecules. Oxford University Press, New York

22. Becke AD (1993) J Chem Phys 98:5648-5652

23. Lee C, Yang W, Par RG (1993) Phys Rev B 37:785-769

24. Krishnan R, Binkley JS, Seeger R, Pople JA (1980) J Chem Phys $72: 650-654$

25. Fukui K (1970) J Phys Chem 74:4161-4163

26. Baker J, Wolinski K, Malagoli M, Kinghorn D, Wolinski P, Magyarfalvi G, Saebo S, Janowski T, Pulay P (2009) J Comput Chem 30(2):317-335

27. PQS version 3.3, Parallel Quantum Solutions; 2013 Green Acres Road, Fayetteville, AR 72703, USA

28. Boys SF, Bernardi F (1970) Mol Phys 19:553-566 